\title{
Dynamic Behaviour of the Patented Kobold Tidal Current Turbine: Numerical and Experimental Aspects
}

\author{
D. P. Coiro, A. De Marco, F. Nicolosi, S. Melone, F. Montella
}

This paper provides a summary of the work done at DPA on numerical and experimental investigations of a novel patented vertical axis and variable pitching blades hydro turbine designed to harness energy from marine tidal currents. Ponte di Archimede S.p.A. Company, located in Messina, Italy, owns the patented KOBOLD turbine that is moored in the Messina Strait, between the mainland and Sicily. The turbine has a rotor with a diameter of 6 meters, three vertical blades of 5 meters span with a $0.4 \mathrm{~m}$ chord ad hoc designed curved airfoil, producing high lift with no cavitation. The rated power is $160 \mathrm{~kW}$ with $3.5 \mathrm{~m} / \mathrm{s}$ current speed, which means $25 \%$ global system efficiency. The VAWT and VAWT_DYN computer codes, based on Double Multiple Steamtube, have been developed to predict the steady and dynamic performances of a cycloturbine with fixed or self-acting variable pitch straight-blades. A theoretical analysis and a numerical prediction of the turbine performances as well as experimental test results on both a model and the real scale turbine will be presented and discussed.

Keywords: vertical-axis-hydro-turbine, variable pitch, Double-Multiple-Streamtube, tidal currents, tidal energy.

\begin{tabular}{|c|c|c|}
\hline \multicolumn{3}{|c|}{ Notation } \\
\hline Symbol & Unit & Description \\
\hline$a$ & & Interference factor \\
\hline$c$ & $\mathrm{~m}$ & Blade chord length \\
\hline$C_{\mathrm{d}}$ & & Airfoil drag coefficient \\
\hline$C_{1}$ & & Airfoil lift coefficient \\
\hline$C_{m c / 4}$ & & $\begin{array}{l}\text { Airfoil quarter chord pitching moment } \\
\text { coefficient }\end{array}$ \\
\hline$C_{\mathrm{D}}$ & & Blade drag coefficient \\
\hline$C_{\mathrm{L}}$ & & Blade lift coefficient \\
\hline$C_{\mathrm{p}}$ & & Turbine performance coefficient \\
\hline$C_{\mathrm{q}}$ & & Turbine torque coefficient \\
\hline$D$ & $\mathrm{~N}$ & Drag \\
\hline $\mathrm{d} F$ & $\mathrm{~N}$ & $\begin{array}{l}\text { Elementary force acting on the elemen- } \\
\text { tary actuator disk }\end{array}$ \\
\hline$I_{\mathrm{p}}$ & $\mathrm{kgm}^{2}$ & Blade moment of inertia \\
\hline$I_{\mathrm{T}}$ & $\mathrm{kgm}^{2}$ & Turbine moment of inertia \\
\hline$L$ & $\mathrm{~N}$ & Lift \\
\hline M & $\mathrm{Nm}$ & Instantaneous turbine torque \\
\hline$M C$ & $\mathrm{Nm}$ & Instantaneous load torque \\
\hline$M_{\mathrm{c} / 4}$ & $\mathrm{Nm}$ & Quarter chord pitching moment \\
\hline$M_{\mathrm{m}}$ & $\mathrm{Nm}$ & Average turbine torque \\
\hline$N$ & $\mathrm{~N}$ & Blade radial force \\
\hline$N_{\mathrm{b}}$ & & Number of blades \\
\hline$P$ & W & Instantaneous turbine mechanical power \\
\hline$P_{\mathrm{m}}$ & $\mathrm{W}$ & Average turbine mechanical power \\
\hline$R$ & $\mathrm{~m}$ & Turbine radius \\
\hline $\operatorname{Re}$ & & Blade Reynolds number \\
\hline$S$ & $\mathrm{~m}^{2}$ & Turbine frontal area \\
\hline$T$ & $\mathrm{Nm}$ & Blade tangential force \\
\hline$V$ & $\mathrm{~m} / \mathrm{s}$ & Local velocity \\
\hline$V_{\mathrm{R}}$ & $\mathrm{m} / \mathrm{s}$ & Tip speed \\
\hline
\end{tabular}

\begin{tabular}{|c|c|c|}
\hline$V_{\infty}$ & $\mathrm{m} / \mathrm{s}$ & Asymptotic velocity \\
\hline$x_{c / 4}$ & $\begin{array}{l}\text { \%blade } \\
\text { chord }\end{array}$ & Blade aerodynamic centre position \\
\hline$x_{\text {hinge }}$ & $\begin{array}{l}\text { \%blade } \\
\text { chord }\end{array}$ & Floating hinge position \\
\hline$\alpha$ & rad & Blade angle of attack \\
\hline$\alpha_{\tan }$ & $\mathrm{rad}$ & $\begin{array}{l}\text { Angle between the local velocity and the } \\
\text { local tangent at the blade }\end{array}$ \\
\hline$\alpha_{\mathrm{ZV}}$ & $\mathrm{rad}$ & Blade pitch angle \\
\hline$\ddot{\alpha}$ & $\mathrm{rad} / \mathrm{s}^{2}$ & Blade pitch angle acceleration \\
\hline$\lambda$ & & Tip speed ratio $=\Omega \mathrm{R} / \mathrm{V}_{\infty}$ \\
\hline$\rho$ & $\mathrm{kg} / \mathrm{m}^{3}$ & Fluid density \\
\hline$\sigma$ & & Solidity $=N_{\mathrm{b}} c / R$ \\
\hline$\theta$ & rad & Blade azimuth angle \\
\hline$\ddot{\theta}$ & $\mathrm{rad} / \mathrm{s}^{2}$ & Turbine acceleration \\
\hline$\Omega$ & $\mathrm{rad} / \mathrm{s}$ & Turbine angular velocity \\
\hline
\end{tabular}

Subscript

d Conditions at the downwind actuator disk

$\mathrm{u} \quad$ Conditions at the upwind actuator disk

h Hinge

\section{Introduction}

Marine current energy is a type of renewable energy resource that has been less exploited than wind energy. Only recent years, have some countries devoted funds to research aimed at developing tidal current power stations. Tidal current turbines, as in the wind community, can be divided into vertical-axis and horizontal axis types. Although horizontal axis turbines have been more widely used than vertical axis types for wind energy exploitation, vertical axis turbines could present significant advantages for tidal current exploitation, because they are simple to build and reliable in working conditions. Therefore, at beginning of the studies 
vertical axis wind turbines were taken as models for hydro-turbines. The blades of Darrieus-type vertical axis wind turbines are fixed, and they perform well when the blade solidity is low and the working speed is high. For this reason, the first hydro-turbines were impossible to start. A variable-pitch blade system can be a solution to this problem. Some prototypes with different variants of this system have therefore been developed around the world: the Kobold turbine in the Strait of Messina, Italy; the cycloidal turbine in Guanshan, China; the moment-control turbine at Edinburgh University, UK; and the mass-stabilised system turbine by Kirke and Lazauskas in Inman Valley, South Australia. The Kobold turbine has been under development since 1997: the rotor has a self-acting variable pitch and the Kobold blades have an ad hoc designed airfoil, called HLIFT, to be cavitation free and to have high lift performance. The methods for calculating the hydrodynamic performances of vertical axis turbines also come from wind turbines: in the 1970s Templin developed the Single-Disk Single-Tube model, and then Strickland put forward the Single-Disk Multi-Tube model. In the 1980s Paraschivoiu introduced the Double-Disk Multi-Tube model. The VAWT and VAWT_DYN computer codes, based on this theory, have been developed to predict the steady and dynamic performances of a cycloturbine with fixed or self-acting variable pitch straight-blades. The numerical results have been compared with two sets of experimental data: one set is obtained from wind tunnel tests on a scaled model, and the other set is based on field data from the Kobold prototype.

\section{Double multiple streamtube}

In order to analyze the flow field around a vertical axis turbine, a DMS model was used. The DMS model is an evolution of the previous "momentum models": the single streamtube model, the multiple streamtube model and the double streamtube model [1]. The DMS model [2] assumes that the flow through the rotor can be modelled by examining the flow through several streamtubes, and the flow disturbance, produced by the rotor is determined by equating the aerodynamic forces on the turbine rotor to the time rate of change in momentum through the rotor as depicted in Fig. 1. In the DMS model, the flow velocities vary in both the upwind and downwind regions of the streamtube, as well as varying from streamtube to streamtube. So DMS is able to analyse the interference between the downwind blade and the upwind blade's
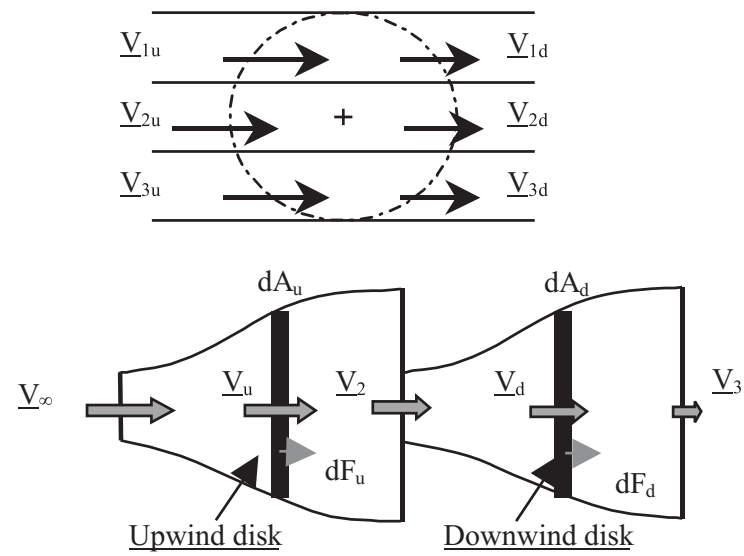

Fig. 1: Double multiple streamtube model wake in order to evaluate more accurately the local value of the velocity and the instantaneous blade load. As shown in Fig. 1., the rotor is modelled as a series of elementary streamtubes, and each streamtube is modelled with two actuator disks in series. Across the actuator disk the pressure drops and this drop is equivalent to the streamwise force $\mathrm{d} F$ on the actuator disk divided by the actuator disk area $\mathrm{d} A$.

The elementary force $\mathrm{d} F_{\mathrm{u}}$ and $\mathrm{d} F_{\mathrm{d}}$, respectively on the upwind and downwind disk, given by the momentum principle, are

$$
\begin{aligned}
& \mathrm{d} F_{\mathrm{u}}=\rho V_{\mathrm{u}} \mathrm{d} A_{\mathrm{u}}\left(V_{\infty}-V_{2}\right) \\
& \mathrm{d} F_{\mathrm{d}}=\rho V_{\mathrm{d}} \mathrm{d} A_{\mathrm{d}}\left(V_{2}-V_{3}\right)
\end{aligned}
$$

where $V_{\mathrm{d}}$, which is the velocity on the downwind actuator disk, is influenced by the velocity $V_{\mathrm{u}}$ on the upwind actuator disk. The elementary forces $\mathrm{d} F$ on the actuator disks may be calculated using Blade Element Theory.

If the upwind and downwind interference factors are defined as

$$
a_{\mathrm{u}}=\frac{V_{\infty}-V_{\mathrm{u}}}{V_{\infty}} \quad a_{\mathrm{d}}=\frac{V_{\infty}-V_{\mathrm{d}}}{V_{\infty}}
$$

the mathematical problem can be reduced to the calculation of $a_{\mathrm{u}}$ and $a_{\mathrm{d}}$. Because of the non-linearity of the equations, the problem must be resolved iteratively. If the rotor blades have a fixed pitch angle or an assigned pitch variation (i.e. sinusoidal like in Pinson, cycloidal, etc.), the mathematical model is reduced, for each elementary streamtube, to an equation for the momentum balance for the upwind actuator disk and an equation for the momentum balance for the downwind actuator disk.

$$
\begin{aligned}
a_{\mathrm{u}}\left(1-a_{\mathrm{u}}\right)= & \frac{1}{|\operatorname{sen} \theta|} \frac{\sigma}{8 \pi}\left(\frac{V_{\mathrm{Ru}}}{V_{\infty}}\right)^{2}\left\{C_{\mathrm{lu}} \operatorname{sen}\left[(2 \pi-\theta)+\alpha_{\mathrm{tanu}}\right]\right. \\
& \left.-C_{\mathrm{du}} \cos \left[(2 \pi-\theta)+\alpha_{\mathrm{tanu}}\right]\right\} \\
\left(1-a_{\mathrm{d}}\right)\left(a_{\mathrm{d}}-2 a_{\mathrm{u}}\right)= & \frac{1}{|\operatorname{sen} \theta|} \frac{\sigma}{8 \pi}\left(\frac{V_{\mathrm{Rd}}}{V_{\infty}}\right)^{2}\left[C_{\mathrm{ld}} \operatorname{sen}\left(\theta+\alpha_{\mathrm{tand}}\right)\right. \\
& \left.-C_{\mathrm{dd}} \cos \left(\theta+\alpha_{\mathrm{tand}}\right)\right]
\end{aligned}
$$

If the rotor blades have a self-acting variable pitch angle [3], [4], [5], another equation is also necessary for each actuator disk: the hinge moment equilibrium. In this case, in fact, the blade is partially free to pitch under the action of the aerodynamic and inertia forces so as to reduce the angle of attack

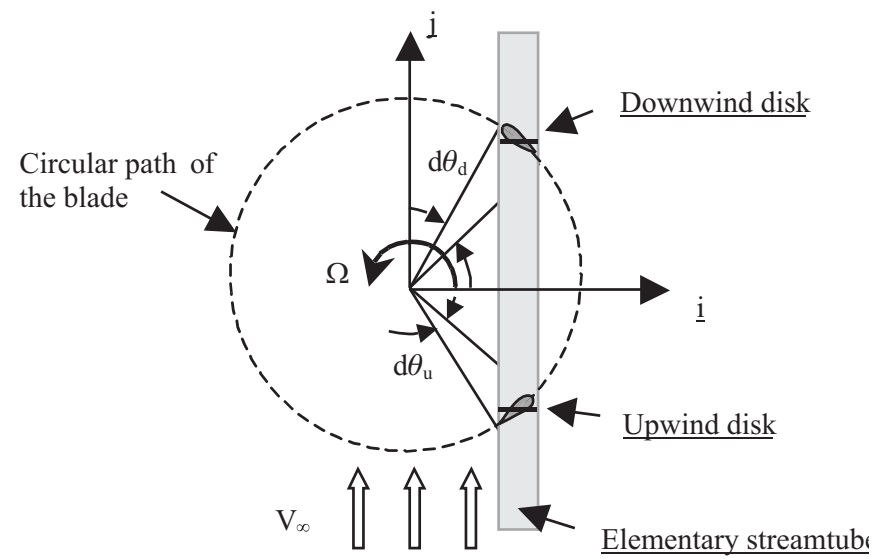




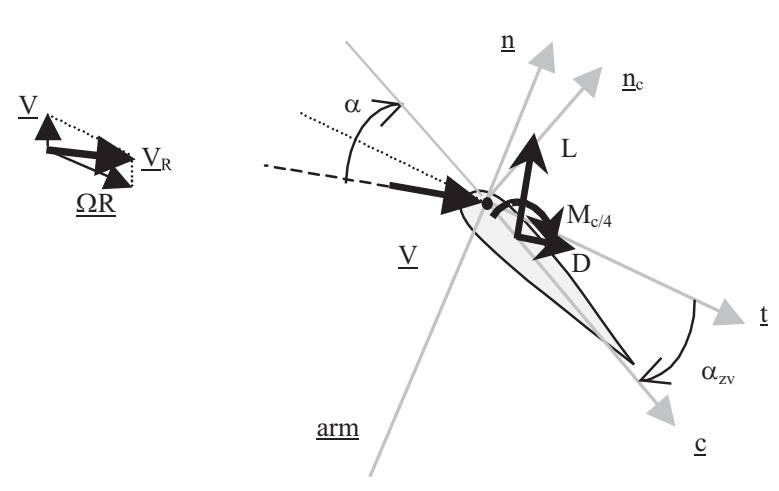

Fig. 2: Hinge moment equilibrium

and hence the tendency of the blade to stall. The allowed angular swinging of the blade is limited by the presence of two blocks. In this way the mathematical model is represented by two systems of equations, each constituted of two equations: momentum balance and hinge moment equilibrium. For one blade and for the upwind actuator disk

$$
\begin{aligned}
& a_{\mathrm{u}}\left(1-a_{\mathrm{u}}\right)= \frac{1}{\left|\operatorname{sen} \theta_{\mathrm{u}}\right|} \frac{\sigma}{8 \pi}\left(\frac{V_{\mathrm{Ru}}}{V_{\infty}}\right)^{2}\left\{C_{\mathrm{lu}}\left(\alpha_{\mathrm{tanu}}, \alpha_{\mathrm{zvu}}, \operatorname{Re}_{\mathrm{u}}\right)\right. \\
& \cdot \operatorname{sen}\left(\theta_{\mathrm{u}}+\alpha_{\mathrm{tanu}}\right)-C_{\mathrm{du}}\left(\alpha_{\mathrm{tanu}}, \alpha_{\mathrm{zvu}}, \operatorname{Re}_{\mathrm{u}}\right) \\
&\left.\cdot \cos \left(\theta_{\mathrm{u}}+\alpha_{\mathrm{tanu}}\right)\right\} \\
& C_{\mathrm{mc} / 4}\left(\alpha_{\mathrm{tanu}}, \alpha_{\mathrm{zvu}}, \operatorname{Re}_{\mathrm{u}}\right)-C_{\mathrm{nu}}\left(\alpha_{\mathrm{tanu}}, \alpha_{\mathrm{zvu}}, \operatorname{Re}_{\mathrm{u}}\right) \\
& \cdot\left(\bar{x}_{\mathrm{c} / 4}-\bar{x}_{\mathrm{cer}}\right) \cdot \cos \alpha_{\mathrm{zvu}} \\
&-C_{\mathrm{tu}}\left(\alpha_{\mathrm{tanu}}, \alpha_{\mathrm{zvu}}, \operatorname{Re}_{\mathrm{u}}\right) \\
& \cdot\left(\bar{x}_{\mathrm{c} / 4}-\bar{x}_{\mathrm{cer}}\right) \cdot \operatorname{sen} \alpha_{\mathrm{zvu}}=0
\end{aligned}
$$

For the downwind actuator disk

$$
\begin{aligned}
&\left(1-a_{\mathrm{d}}\right)\left(a_{\mathrm{d}}-\right.\left.2 a_{\mathrm{u}}\right)=\frac{1}{\left|\operatorname{sen} \theta_{\mathrm{d}}\right|} \frac{\sigma}{8 \pi}\left(\frac{V_{\mathrm{Rd}}}{V_{\infty}}\right)^{2} \\
&\left\{C_{\mathrm{ld}}\left(\alpha_{\mathrm{tand}}, \alpha_{\mathrm{zvd}}, \operatorname{Re}_{\mathrm{d}}\right)\right. \\
& \cdot \operatorname{sen}\left(\theta_{\mathrm{d}}+\alpha_{\mathrm{tand}}\right)-C_{\mathrm{dd}}\left(\alpha_{\mathrm{tand}}, \alpha_{\mathrm{zvd}}, \operatorname{Re}_{\mathrm{d}}\right) \\
&\left.\cdot \cos \left(\theta_{\mathrm{d}}+\alpha_{\mathrm{tand}}\right)\right\} \\
& C_{\mathrm{mc} / 4}\left(\alpha_{\mathrm{tand}}, \alpha_{\mathrm{zvd}}, \operatorname{Re}_{\mathrm{d}}\right)-C_{\mathrm{nd}}\left(\alpha_{\mathrm{tand}}, \alpha_{\mathrm{zvd}}, \operatorname{Re}_{\mathrm{d}}\right) \\
& \cdot\left(\bar{x}_{\mathrm{c} / 4}-\bar{x}_{\mathrm{cer}}\right) \cdot \cos \alpha_{\mathrm{zvd}} \\
&-C_{\mathrm{td}}\left(\alpha_{\mathrm{tand}}, \alpha_{\mathrm{zvd}}, \operatorname{Re}_{\mathrm{d}}\right) \\
& \cdot\left(\bar{x}_{\mathrm{c} / 4}-\bar{x}_{\mathrm{cer}}\right) \cdot \operatorname{sen} \alpha_{\mathrm{zvd}}=0
\end{aligned}
$$

The instantaneous torque and power produced by the blade are given by the moment equilibrium around the turbine axis

$$
\begin{aligned}
M= & N\left(x_{\mathrm{c} / 4}-x_{\text {hinge }}\right) \cos \alpha_{\mathrm{Zv}} \\
& -T\left[R-\left(x_{\mathrm{c} / 4}-x_{\text {hinge }}\right) \operatorname{sen} \alpha_{\mathrm{zv}}\right] \\
P= & M \cdot \Omega
\end{aligned}
$$

To obtain the mean torque and mechanical power produced by $N_{\mathrm{b}}$ blades in a revolution it is necessary to average the instantaneous values.

$$
\begin{aligned}
M_{\mathrm{m}}=\frac{N_{\mathrm{b}}}{2 \pi} \int_{0}^{2 \pi}\left\{\mathrm{N}\left(x_{\mathrm{c} / 4}-x_{\text {hinge }}\right) \cos \alpha_{\mathrm{zv}}\right. \\
\left.\quad-T\left[R-\left(x_{\mathrm{c} / 4}-x_{\text {hinge }}\right) \operatorname{sen} \alpha_{\mathrm{zv}}\right]\right\} \mathrm{d} \theta,
\end{aligned}
$$

$$
\begin{aligned}
P_{\mathrm{m}}=\frac{N_{\mathrm{b}} \Omega}{2 \pi} \int_{0}^{2 \pi}\left\{\mathrm{N}\left(x_{\mathrm{c} / 4}-x_{\text {hinge }}\right) \cos \alpha_{\mathrm{zv}}\right. \\
\left.\quad-T\left[R-\left(x_{\mathrm{c} / 4}-x_{\text {hinge }}\right) \operatorname{sen} \alpha_{\mathrm{zv}}\right]\right\} \mathrm{d} \theta .
\end{aligned}
$$

To simulate dynamic performances, we have to resolve only the equation of the moment equilibrium around turbine axis (10) for fixed blade or $N_{\mathrm{b}}+1$ equations for $N_{\mathrm{b}}$ floating blades around their hinge axis (11).

$$
\begin{aligned}
& I_{T} \ddot{\vartheta}=\sum_{i=1}^{N_{\mathrm{b}}} M_{i}-M_{\mathrm{C}} \\
& I_{\mathrm{P}}\left(\ddot{\alpha}_{\mathrm{zv} 1}-\ddot{\vartheta}\right)=M_{\mathrm{h} 1} \\
& I_{\mathrm{P}}\left(\ddot{\alpha}_{\mathrm{zv} 2}-\ddot{\vartheta}\right)=M_{\mathrm{h} 2} \\
& I_{\mathrm{P}}\left(\ddot{\alpha}_{\mathrm{zv} 3}-\ddot{\vartheta}\right)=M_{\mathrm{h} 3} \\
& \ldots \\
& I_{\mathrm{P}}\left(\ddot{\alpha}_{\mathrm{zvn}}-\ddot{\vartheta}\right)=M_{\mathrm{hn}}
\end{aligned}
$$

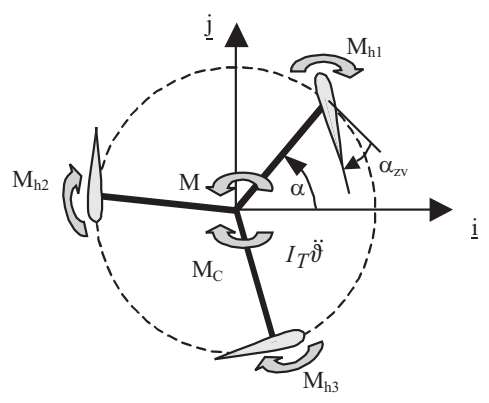

Fig. 3: Torques on a Kobold turbine

\section{Airfoils and aerodynamic characteristics}

The rotor performances were tested using five airfoils: three symmetrical airfoils NACA 0012, 0015, 0018 and two cambered airfoils NACA 4415 and HLIFT18. The last named was designed at DPA; it is a high lift [6], [7] and no cavitating airfoil. It has in fact been designed to work in the water on the KOBOLD turbine. For the NACA airfoils, data was taken from the literature [2], [8] while for the HLIFT18 airfoil, TBVOR [9], [10], [11] codes were used to generate the values of the aerodynamic coefficients. The airfoil 2D data is corrected, in VAWT and VAWT_DYN codes [12], to take into account the three-dimensional effects due to the blade finite aspect ratio. To take into account the three-dimensional effects, Prandtl's lifting line theory, extended to treat high lift flow, has been used, evaluating in this way the $3 \mathrm{D}$ lift curve beginning from the $2 \mathrm{D}$ data. This theory is valid only in the linear zone of the lift curve but with care it can also be extended to non linear conditions. The total blade drag coefficient is the sum of the airfoil drag coefficient $\left(C_{\mathrm{d}}\right)$, due to skin friction, and the induced drag coefficient. To take into account the interference between the blade and the support arms, a further drag coefficient increment, $\Delta C_{\mathrm{D}}$, has been introduced. Moreover, 2D post-stall modelling, based on the Viterna-Corrigan correlation method, has been introduced to extend the 2D aerodynamic coefficients to this angle range. 

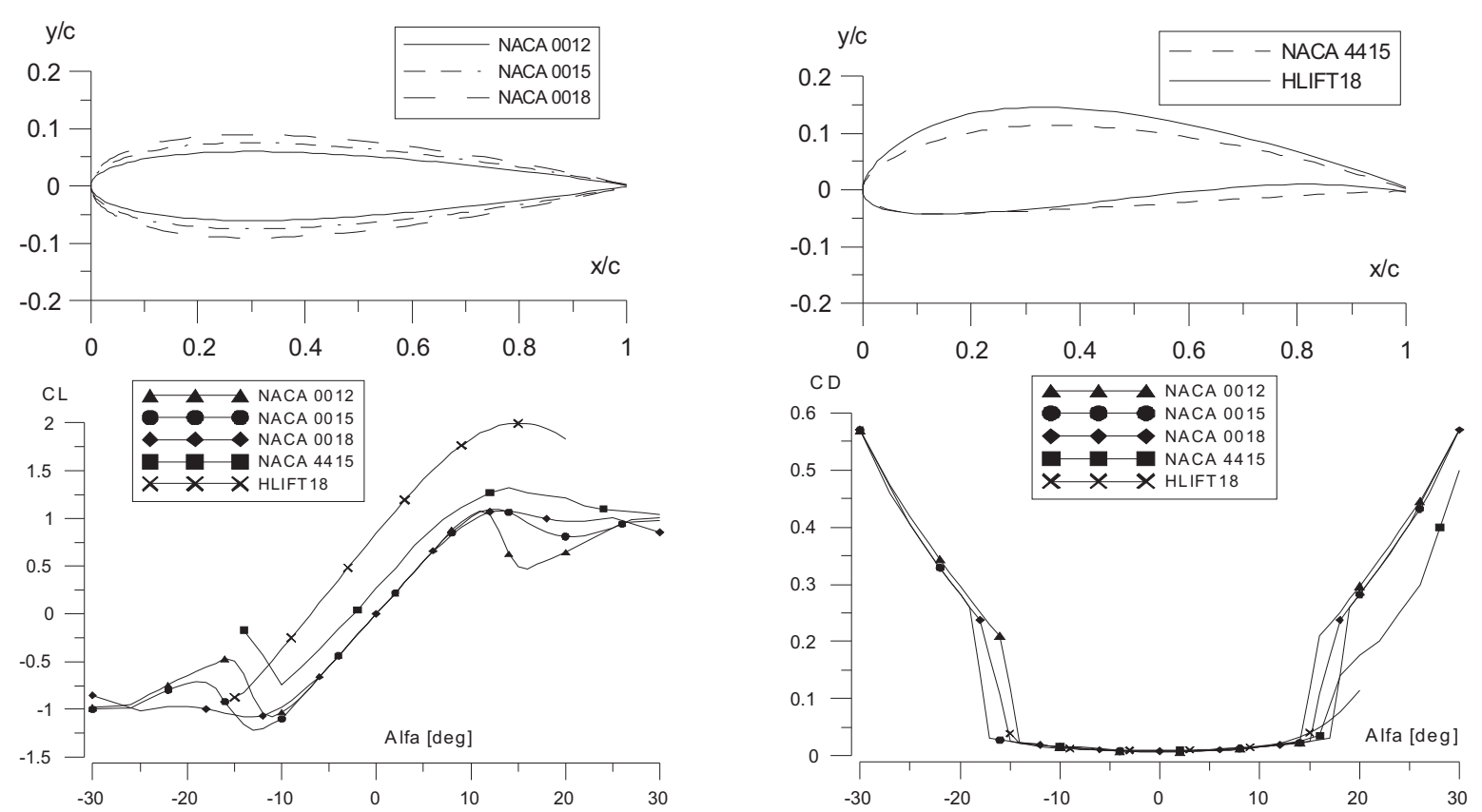

Fig. 4: Airfoils tested and aerodynamic characteristics $(\operatorname{Re}=10 \mathrm{e} 6)$
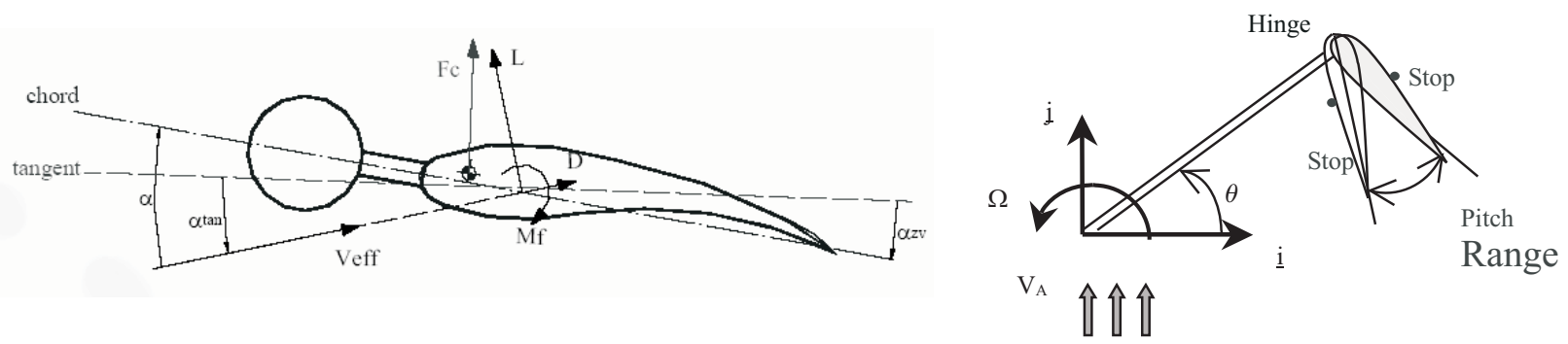

Fig. 5: Balancing mass and blade stops

\section{Experimental models}

The reported experimental data is divided into two parts:

- Experimental data measured in the DPA wind-tunnel at the University of Naples on a small straight-bladed cycloturbine, which was designed, developed and assembled at DPA [13];

- Experimental data measured in water on the "Kobold" prototype (real scale) [12], [14].

Both the DPA straight-bladed cycloturbine (Model A) and the "Kobold" prototype (Model B) will be described, as follows. Both turbines have variable pitch blades with a self-acting system, made up of two balancing masses for each blade. In this way, the centre of gravity of the blade can be moved into its optimal position in order to optimize the global performance of the rotor, and, using two stops, the pitch blade range can be limited, as shown in Fig. 5 .

Model A in the DPA wind-tunnel is shown in fig. 6. Using different stop positions, it was possible to test different pitch angle ranges, and while using different numbers of blades it was possible to take into account different solidity $[\mathrm{Nc} / \mathrm{R}]$ values. Model A has the following geometric parameters:
number of blades tested
$2,3,4,6$
blade chord
$0.15 \mathrm{~m}$

$\begin{array}{ll}\text { blade airfoil } & \text { NACA } 0018 \\ \text { blade span } & 0.8 \mathrm{~m} \\ \text { Aspect Ratio } & 5.33 \\ \text { radius } & 1.05 \mathrm{~m} \\ \text { number of radial arm } & 4,6,8,12 \\ \text { arm chord } & 0.05 \mathrm{~m} \\ \text { solidity 1 } & 0.286 \\ \text { solidity 2 } & 0.428 \\ \text { solidity } 3 & 0.571 \\ \text { solidity } 4 & 0.857\end{array}$

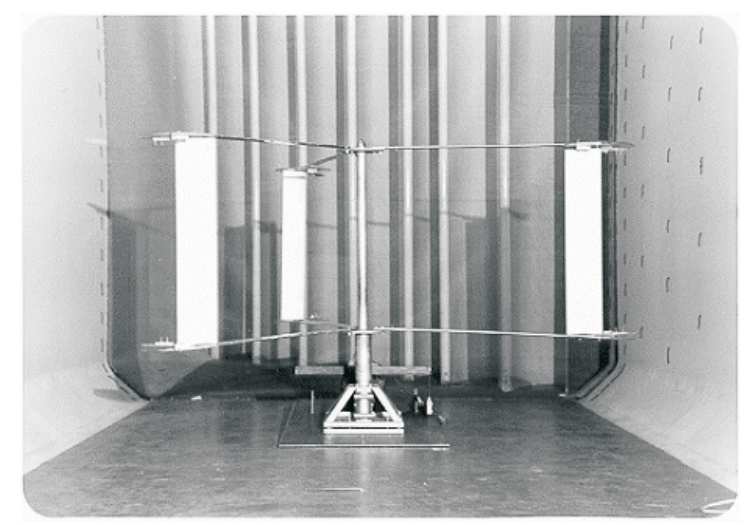

Fig. 6: DPA straight-bladed cycloturbine (Model A) 

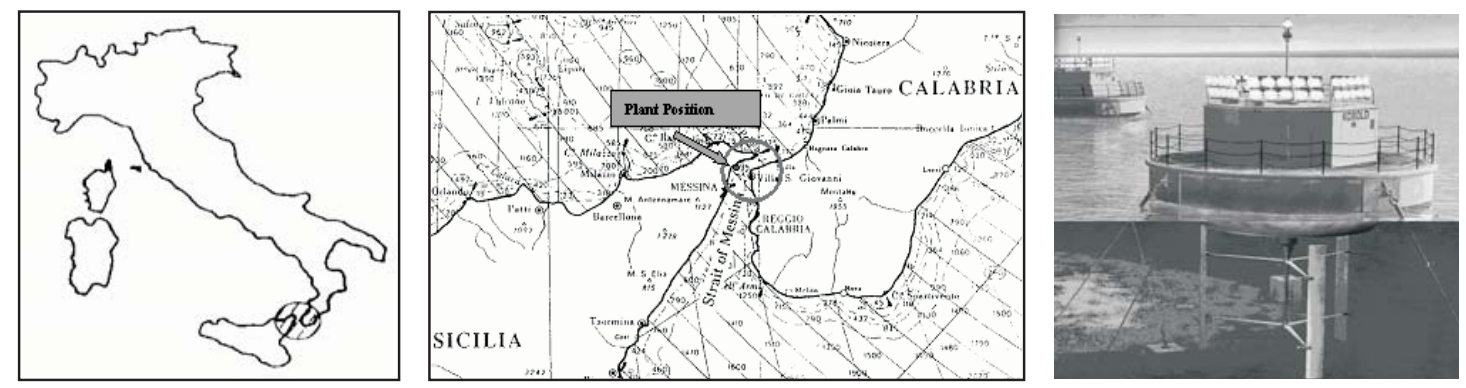

Fig. 7: The Strait of Messina, the position of the plant and a picture of the plant
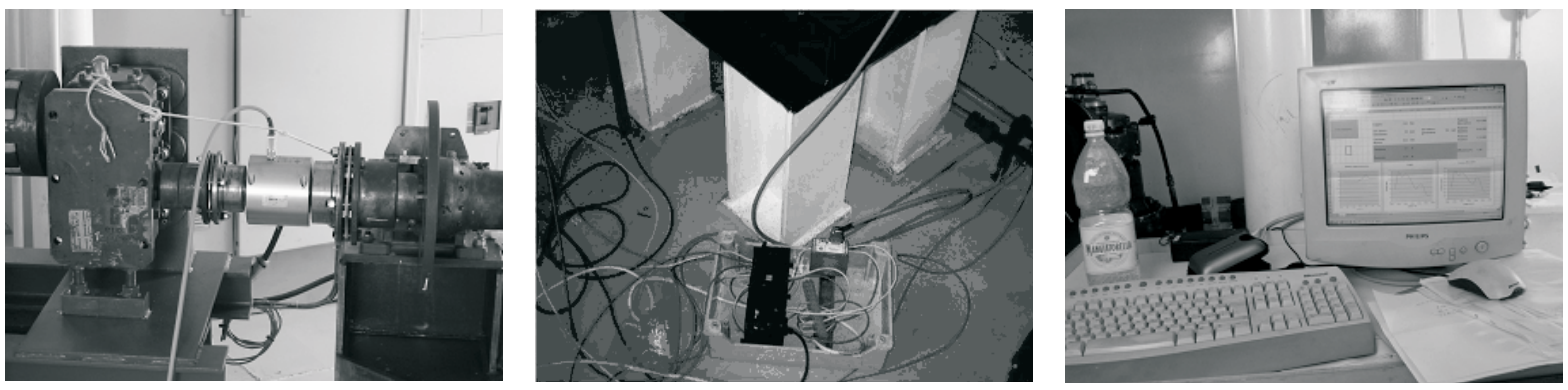

Fig. 8: The torque-meter, the PLC and the PC

The "Kobold" prototype (Model B) lies out in the Strait of Messina, close to the Sicilian shore, facing a village called Ganzirri, close to the lake of the same name, as shown in Fig. 7.

In this site the peak current speed is $2 \mathrm{~m} / \mathrm{s}$ (4 knots), the sea depth is 20 meters and the plant has been moored 150 meters offshore. The current changes direction every $6 \mathrm{hrs}$ and 12 minutes, and the amplitude period is equal to 14 days. A high lift airfoil, called H-LIFT18, is used for the blade sections and has been specially designed at DPA to be cavitation free and to optimise the turbine performance. Two arms sustain each blade and the arms have been streamlined using another ad hoc designed symmetrical airfoil. The turbine has a very high starting torque, being able in this way to start spontaneously, also with electrical load connected, without the need for any starting devices. The ENERMAR plant is composed of the turbine rotor hanging under a floating buoy that contains the remaining mechanical and

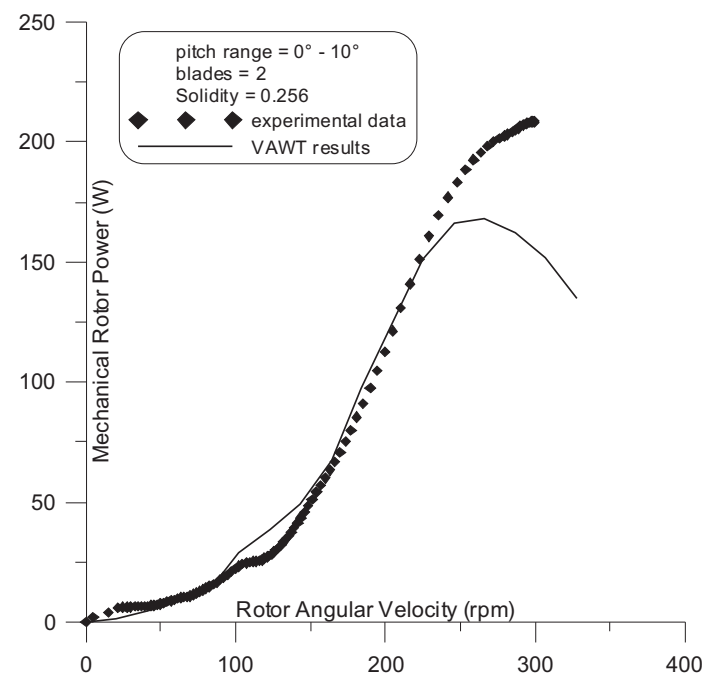

Fig. 9: Experimental data and VAWT results (Model A) electrical parts to deliver energy to the grid, as shown in Fig. 7. The rotor has a diameter of 6 meters with 6 radial arms holding three blades with a five-meter span and with a chord of $0.4 \mathrm{~m}$ employing the H-LIFT1 8 airfoil leading to an aspect ratio of 12.5 and to solidity $\sigma=0.4$. The acquisition data system is made up of a torque-meter, a tidal current speed-meter and an RPM counter all connected to a PLC that converts analog signals to digital data transferring them to a PC. Data handling software has been developed to monitor the acquired data in real time. Fig. 8 shows some components of the acquisition data system. The PLC also acts as an electrical load controller to keep the turbine working always at its maximum efficiency independently from the current speed.

\section{Experimental tests}

Fig. 9 and Fig. 10 compare the VAWT code numerical results with the experimental data measured on Model A, for

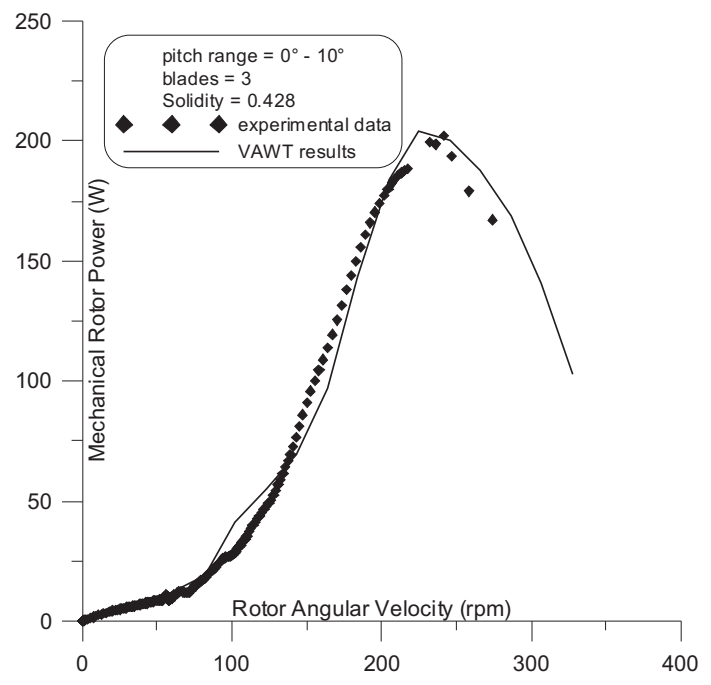



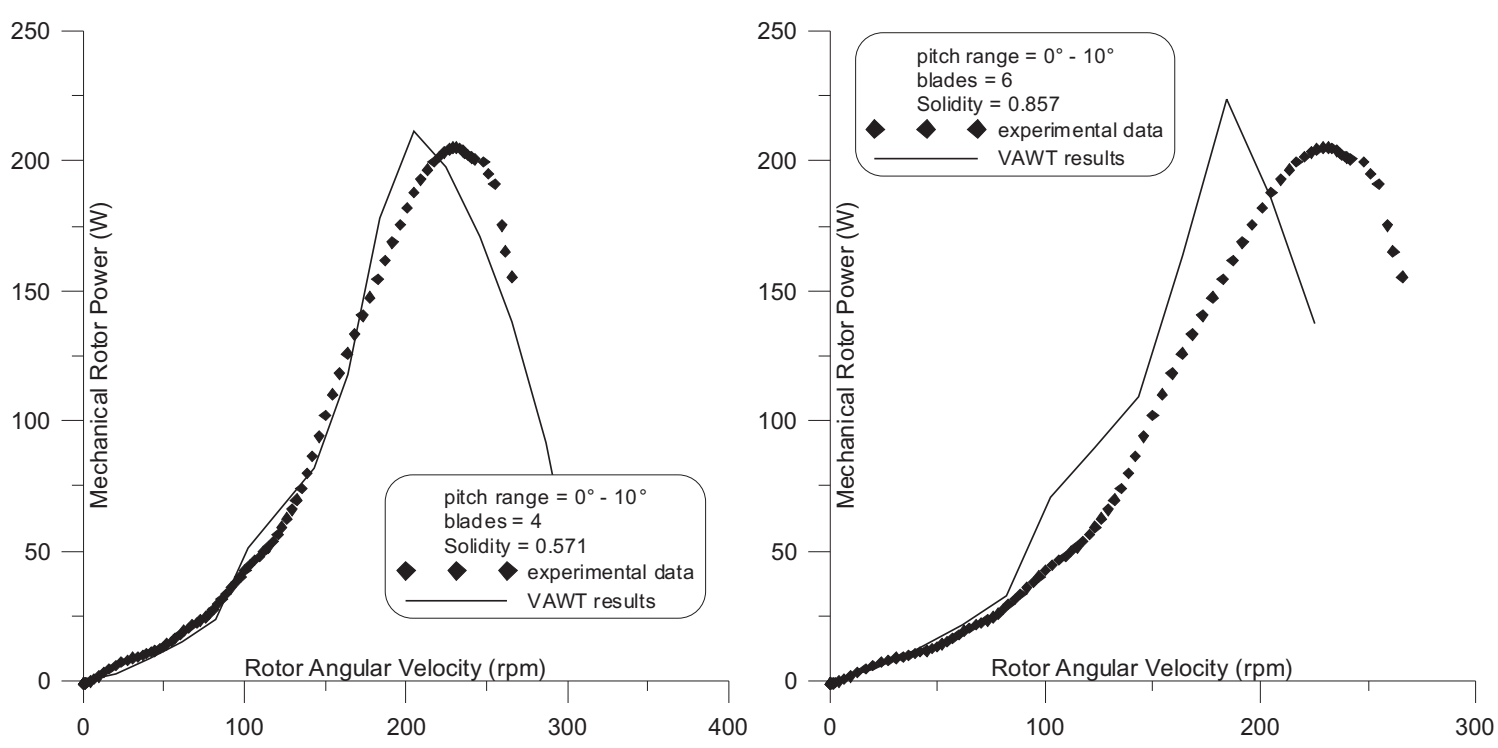

Fig. 10: Experimental data and VAWT results (Model A)

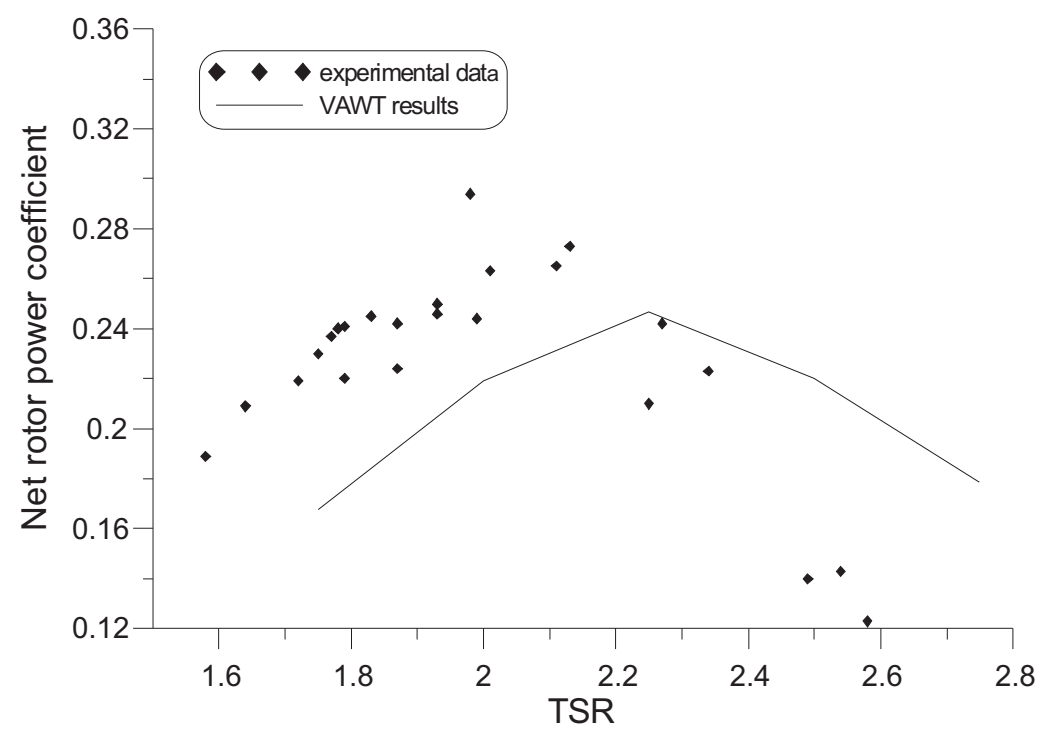

Fig. 11: Experimental data and VAWT results (Model B)
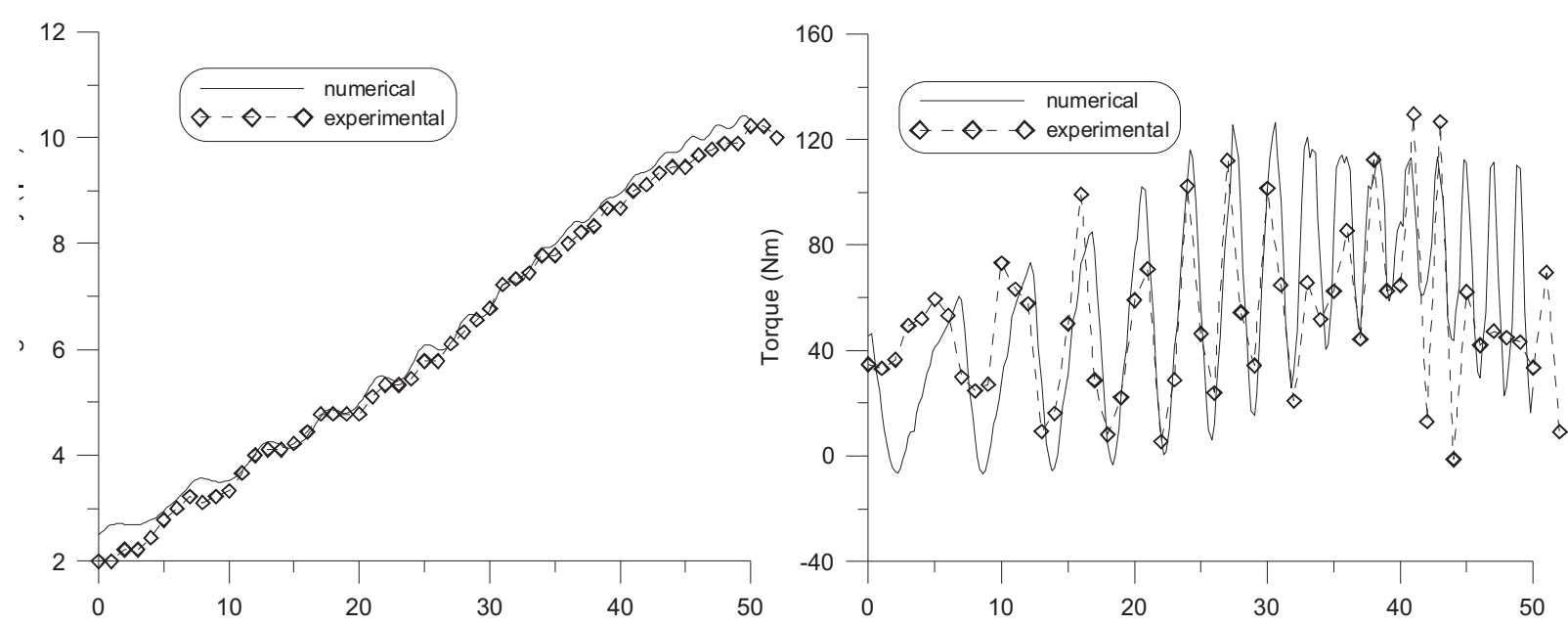

Fig. 12: Experimental data and VAWT_DYN results (Model B) 


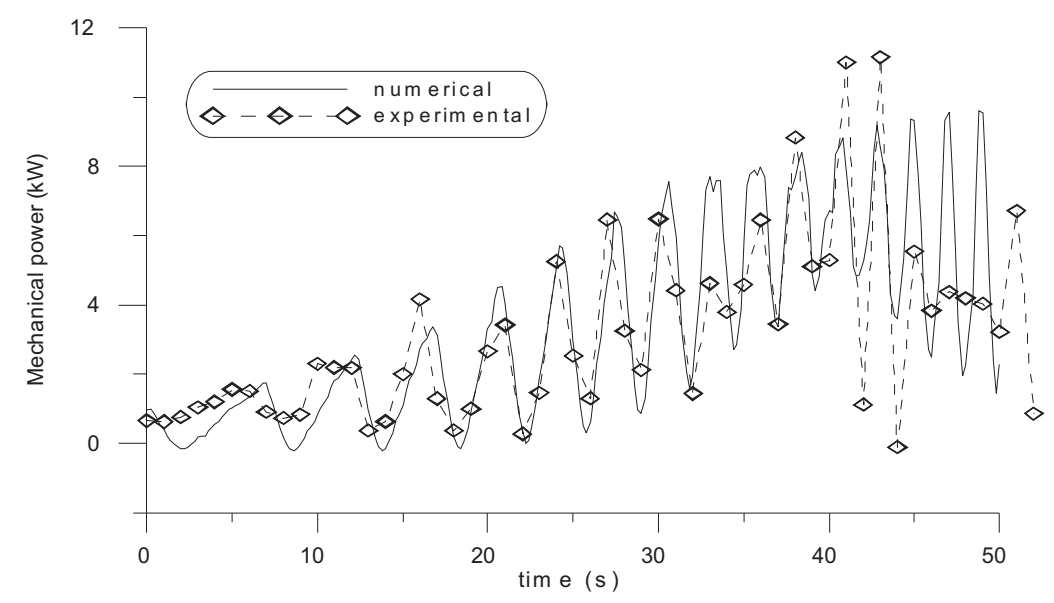

Fig. 13: Experimental data and VAWT_DYN results (Model B)

different blade numbers and different pitch range. The pitch angle is measured between the local tangent to the blade circular path and the blade trailing edge, starting from the tangent in clockwise direction. The power measured is the net rotor power, and the tests are carried out with $9 \mathrm{~m} / \mathrm{s}$ air speed in the DPA wind tunnel for Model A. A comparison of the numerical results with the experimental data shows good agreement, especially for 3 and 4 blades; in the case of 6 blades, the solidity is very high and there is a strong wake effect on each blade. Fig. 11 compares the experimental data measured during field tests in water for the Kobold turbine prototype - model B - with the VAWT code numerical prediction. The net rotor power coefficient is measured, and the tests are carried out with a presumed current speed of $1.4 \mathrm{~m} / \mathrm{s}$, but there is uncertainty around $25 \%$ on the real "undisturbed" current speed value, which is strongly influenced by the location of the current speed meter: this is at present being investigated. Fig. 12 and Fig. 13 show the experimental data and VAWT_DYN code numerical results referred to the starting condition for the Kobold turbine prototype (Model B). The rotor angular velocity variation in time predicted by the code seems to be very accurate, while the rotor torque and power amplitudes are in good agreement only in the first part of the time range: this is probably due to the uncertain value of the numerical predicted losses. The frequency of the torque and power is, however, very well predicted.

\section{Conclusions}

The Double Multiple Steamtube model seems to be good in predicting the vertical axis turbine performances, with fixed or floating blades, expecially for solidity values less than 0.5. This model has been implemented in VAWT and VAWT_DYN codes, which are then capable of predicting both static and dynamic performances of the turbine with very low computing time. In these codes blade 3D effects have been included as well as arm losses, while it is difficult to predict the losses due to other effects. In the field tests, the accuracy of the tidal speed current measurement is a problem, because it is difficult to set the current speed-meter in the "real" undisturbed flow, so the measurements have an uncertainty level around $20 \%$. On the Kobold turbine, the HLIFT18 non-symmetrical and non-cavitating airfoil gives better performance than a symmetrical airfoil, and the self-acting variable pitch system with balancing mass has proven to be simple to build and more reliable than other more complex systems.

\section{References}

[1] Strickland, J. H.: "A Review of Aerodynamic Analysis Methods for Vertical-Axis Wind Turbine.” In: Fifth ASME Wind Energy Symposium, SED - Vol. 2 edited by A. H. P. Swift.

[2] Paraschivoiu, I.: Wind Turbine Design with Emphasis on Darreius Concept. Ecole Polytechnique de Montreal, Polytechnic International Press, 2002.

[3] Kentfield, J. A. C.: "Cycloturbines with Freely Hinged Blades or Freely Hinged Leading Edge Slats.” In: Alternative Energy Sources V. Part C: Indirect Solar/Geothermal. (Editor: T. N. Veziroglu). Amsterdam: Elsevier Science Publishers B. V., 1983, p. 71-86.

[4] Lazauskas, L.: "Three Pitch Control Systems for Vertical Axis Wind Turbines Compared." Wind Engineering, Vol. 16 (1992), No. 5, p. 269-281.

[5] Kirke, B. K., Lazauskas, L.: "Experimental Verification of a Mathematical Model for Predicting the Performance of a Self-Acting Variable Pitch Vertical Axis Wind Turbine." Wind Engineering, Vol. 17 (1993), No. 2, p. 58-66.

[6] Healy, J. V.: "The Influence of Blade Camber on the Output of Vertical Axis Wind Turbine." Wind Engineering, Vol. 2 (1978), No. 3, p. 146-155.

[7] Healy, J. V.: "The Influence of Blade Thickness on the Output of Vertical Axis Wind Turbine." Wind Engineering, Vol. 2 (1978), No. 1, p. 1-9.

[8] Reuss, R. L. et al.: Effects of Surface Roughness and Vortex Generators on the NACA 4415 Airfoil. Report: NREL/TP-442-6472. Golden, Colorado: National Renewable Energy Laboratory, December 1995.

[9] Coiro, D. P., de Nicola, C.: Prediction of Aerodynamic Performance of Airfoils in Low Reynolds Number Flows. In: Low 
Reynolds Number Aerodynamics Conference, Notre Dame, Indiana, U.S.A., June 1989.

[10] Coiro, D. P., de Nicola, C.: "Low Reynolds Number Flows: The Role of The Transition.” In: X Congresso Nazionale AIDAA, Pisa, Ottobre 1989.

[11] Coiro, D. P.: "Convergence Acceleration Procedure for a Viscous/Inviscid Coupling Approach for Airfoil Performances Prediction.” In: XI AIDAA National Congress, Forli', Italy, October 1991.

[12] Montella, F., Melone S.: “Analisi Sperimentale e Numerica del Comportamento Statico e Dinamico di una Cicloturbina ad Asse Verticale.” Aerospace Engineering Bachelor Thesis. Napoli, Italy: Dipartimento di Progettazione Aeronautica, December 2003.

[13] Coiro, D. P., Nicolosi, F.: "Numerical and Experimental Tests for the Kobold Turbine.” In: SINERGY Symposium, Hangzhou, Republic of China, November 1998.

[14] Coiro, D. P. et al.: "Exploitation of Marine Tidal Currents: Design, Installation and Experimental Results for the Patented Kobold Vertical Axis Hydro Turbine."
In: Poster-Session OWEMES 2003. Napoli, Italy, 10-12 April 2003.

Prof. D. P. Coiro

phone: +39081 7683322

fax: +39081624609

e-mail: coiro@unina.it

Dr. A. De Marco

e-mail: agodemar@unina.it

Dr. F. Nicolosi

e-mail: fabrnico@unina.it

Dr. S. Melone

e-mail: stmelone@unina.it

Dr. F. Montella

e-mail: francmont@genie.it

Dipartimento di Progetazione Aeronautica (DPA)

University of Naples "Federico II"

Via Claudio 21, 80125 Naples - Italy 